\title{
Improving plant layout and processing flow of jelly mushroom drink to reduce microbial contamination
}

\author{
${ }^{1,{ }^{*}}$ Changchai, S., ${ }^{1}$ Sumrit, T., ${ }^{2}$ Chunlakan, P. and ${ }^{1}$ Inrirai, P. \\ ${ }^{1}$ Agricultural and Food Engineering, Faculty of Food and Agricultural Technology, Pibulsongkram \\ Rajabhat University, Phitsanulok, Thailand \\ ${ }^{2}$ Agro-Industrial Product Development, Faculty of Food and Agricultural Technology, Pibulsongkram \\ Rajabhat University, Phitsanulok, Thailand
}

\begin{abstract}
Article history:
Received: 21 December 2019 Received in revised form: 17 February 2020

Accepted: 20 February 2020 Available Online: 23 March 2020
\end{abstract}

Keywords:

Jelly mushroom drink,

Cross-contamination,

Process analysis,

Plant layout,

Zoning and barriers

DOI:

https://doi.org/10.26656/fr.2017.4(4).420

\begin{abstract}
This study is aimed to develop the manufacturing process of the jelly mushroom drink using primary good manufacturing practice (GMP) for community enterprise, Phitsanulok, Thailand. The evaluation of the existing production process highlighted that the process had risks of cross-contamination, including from the plant layout, which still lacking in food safety management systems. Therefore, the improvement of process manufacturing and layout planning could be divided into three steps: (1) process analysis, (2) line production development, and (3) design plant layout to prevent and reduce crosscontamination causes. The cross-contamination incidence was reduced upon the improvement of the plant layout and processing as observed from the results of the amount of total plate count were reduced from $1.9 \times 10^{7}$ to $<1 \mathrm{CFU} / \mathrm{mL}$, where yeast and mold and 29 to $8.3 \mathrm{CFU} / \mathrm{mL}$ respectively. Meanwhile, the counts for Salmonella spp. and Staphylococcus aureus were below the detection level, whereas Clostridium perfringens, Bacillus cereus, and Listeria monocytogenes were not detected in all samples.
\end{abstract}

\section{Introduction}

A systematic layout plan allows the activity between the operator and the machine to go smoothly; thus, increasing profitability to the company. A systematic layout plan by applying an efficient production flow will result in the decreased idle time that can hold up the line production process (Apple, 1977). Facility Planning has become an essential issue in the manufacturing industry because it provides essential benefits for the organization. An appropriate method of process analysis and material handling can help to increase production effectiveness and reduce material movement, and also reduce material handling cost (Devi et al., 2015).

Good manufacturing practices (GMPs) are the essential operation required to produce safe foods to ensure that ingredients, products, and packaging are handled safely, and food products are processed in a suitable environment during food production. The Food and Drug Administration (FDA) in Thailand is the unit that ensures consumer protection in health products. The establishment of food production facilities should comply with the Primary GMP for the development of products to ensure quality, standard, and food safety; thus, allowing expansion of the market locally or abroad. These requirements encompass the design and facilities of the establishment, hygienic processing, establishment of hygiene in the premises, personnel hygiene and health of employees, transportation, product information and documentation, and food safety training (Cocker, 2003).

The Ban Tha Chang mushroom cultivation community enterprise located in Phrom Phiram District, Phitsanulok, Thailand, established in 2010. The main products were oyster mushroom and black/white jelly mushroom. The jelly mushroom is processed into a jelly mushroom drink, which is another source of income to the community enterprise. However, the problem encountered by the manufacturer is that the jelly mushroom drink has short shelf life caused by microbial contamination in the processing line, which affected the time for product distribution and product quality. Furthermore, the production line, building, and manufacturing process did not follow good manufacturing practices (GMP). Improving the plant layout and processing flow for factory power used is not more than 5 horsepower (hp). The researchers intended to propose the development of the production process and design plant layout according to GMP and food 
safety guidelines by process analysis to prevent and reduce cross-contamination causes.

\section{Materials and methods}

\subsection{Processing of the jelly mushroom drink}

The Ban Tha Chang mushroom cultivation community enterprise is located in the Phitsanulok province, Thailand. Besides mushroom production, the factory also processing mushrooms to produce the jelly mushroom drink. The jelly mushroom drink was processed using the conventional method before the incorporation of the novel production process. The steps in the production process started with boiling the jelly mushrooms for 30 mins, then ground in a blender. Next, the ingredients comprising of sugar, ground jelly mushrooms, and colouring agent were mixed in boiling water for 30 mins until the mixture became viscous. The mixture was then cooled to temperature room before filling into PET bottles. The previous production capacity was 500 bottles/month or depended on the order quantity. The products that were stored in the refrigerator at $5-8^{\circ} \mathrm{C}$ could be stored for only five days.

\subsection{Process analysis}

The process analysis can be presented in an operation process chart (OPC), and flow process chart (FPC) used as a guideline for the development of plant layout and processing flow to reduce microbial contamination. The OPC is a diagrammatic representation of the flow of materials and a sequence of operations for a given food processing operation (i.e. operations and inspections). Meanwhile, the FPC is a chart that showed the sequence of product flow by all activities recorded in suitable symbols. The symbols of operation, transportation, inspection, delay, and permanent are presented in Table 1. The benefits of OPC and FPC writing helped to simplify the design of a plant layout and improve work method (Singhtaun, 2008).

\subsection{Zoning and barriers}

The plant layout and position of equipment in a processing flow should consider the efficiency and ease of use that occurs after installing all equipment. Plant design uses zoning to help prevent cross-contamination in the production line. The planning of the layout has to consider manufacturing practice and hygiene level. The zoning and barriers are divided as follows: site barrier (non-food production areas); and factory barrier: basic hygiene area (raw materials and finished products) and medium hygiene area (ingredient preparation and general processing), and high hygiene barrier (microbiologically decontaminated products and design risk assessed) (Wierenga and Holah, 2003).

\subsection{Determination of microbiological quality}

The measurement list of microorganisms according to the announcement of the Ministry of Public Health, Thailand, issue 364, subject - food standards on microorganisms that cause disease is as follows: Salmonella spp. (in $25 \mathrm{~mL}$ ), Staphylococcus aureus (in $0.1 \mathrm{~mL})$, Bacillus cereus (CFU/mL), Clostridium perfringens $(\mathrm{CFU} / \mathrm{mL})$, Listeria monocytogenes (in 25 $\mathrm{mL})$, total plate count $(\mathrm{CFU} / \mathrm{mL})$, and yeast and molds $(\mathrm{CFU} / \mathrm{mL})$. All parameters were tested by the Central Laboratory (Thailand) Co., Ltd.

\section{Results and discussion}

\subsection{Process analysis}

The evaluation of the jelly mushroom drink production process found that the risks of crosscontamination occurred while boiling the jelly mushroom drink and the temperature of products in the packing process. Therefore, to effectively design the production flow, the process analysis has to be conducted via assessing the OPC and FPC of the jelly mushroom drink process.

\subsubsection{Operation process chart (OPC)}

The OPC shows the five lines of production in the materials and sequence of operations. The top line of the processing flow comprising of raw materials and package for making jelly mushroom drink production is shown in Figure 1. There were 7 steps of inspections, 5 steps of materials quality, 2 steps of temperature and time

Table 1. Process chart symbols

$\begin{array}{ll}\text { Operation } & \text { Meaning/Action } \\ \text { Inspection } & \text { Produce or process something or change one or more characteristics of the material. } \\ \text { Transport } & \text { Movement of people, materials or other items from one place to another. } \\ \text { Stolay } & \text { Idle time of people, material or machinery (may be accompanied by a time measurement). }\end{array}$


Black/white jelly mushroom

(1)

(1) Washing

(2) Boil 30 minutes

(3) Grinded

1 Quality Inspection

4) Boil water

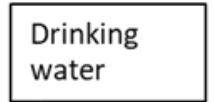

Thality

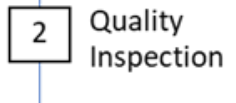

Sugar

Coloring

agent

PET bottle

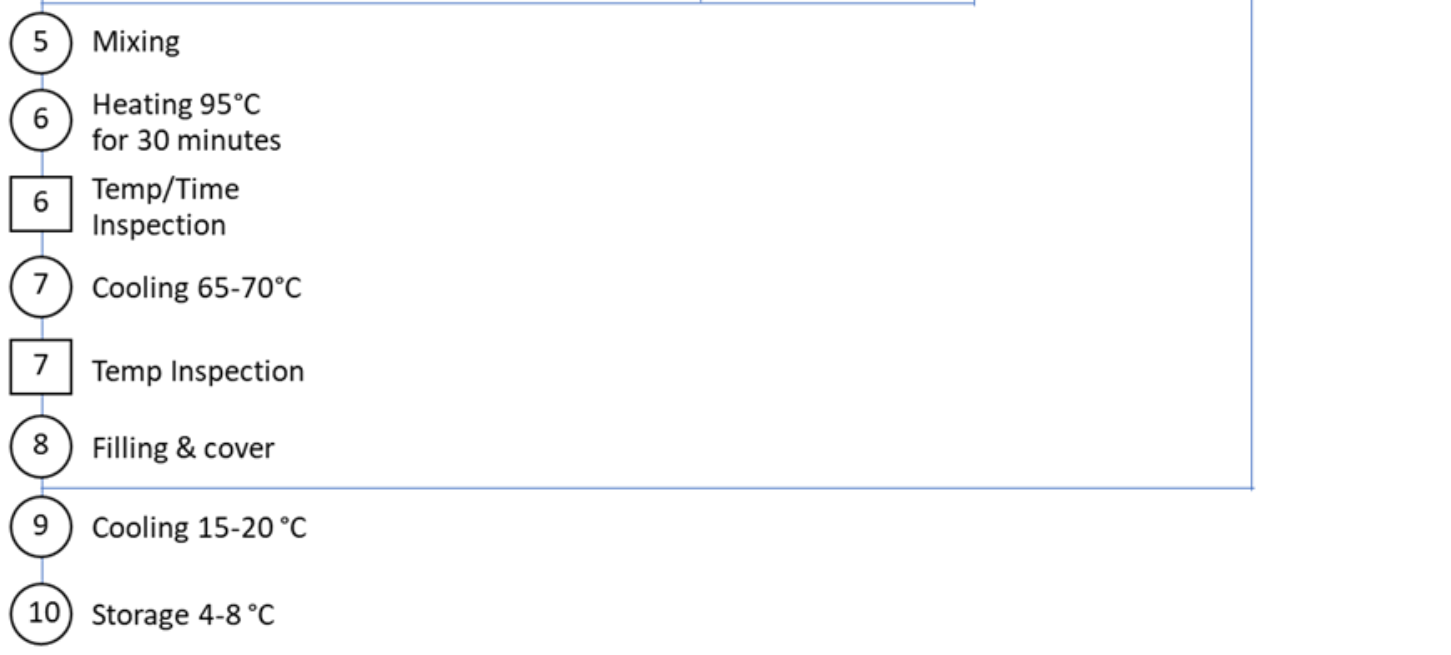

Figure 1. Operation process chart of jelly mushroom production

of heating and cooling and 10 steps of the main processing flow concerning the processing of black/ white jelly mushroom. The preparation of jelly mushroom comprised of 3 steps: (1) washing, (2) boiling in water for 30 mins, (3) draining the water and grinding. After the first line of processing flow, the operator had to clean up the raw material room. The next steps for the preparation of mixture involved two steps: (4) boiling water for ingredient mixing, and (5) adding the ingredients comprising of sugar, ground jelly mushroom, and colouring agent, respectively. The jelly mushroom drink was continuously (6) heated at $95^{\circ} \mathrm{C}$ for 30 mins. Next, (7) the temperature of the product was reduced to $65-70^{\circ} \mathrm{C}$ before (8) filling into PET bottles and sealed. Then the products were (9) immediately immersed in cold water until the temperature dropped to $15-20^{\circ} \mathrm{C}$. The products were then stored at $4-8^{\circ} \mathrm{C}$ with the shelf life of 12 weeks.

\subsubsection{Flow process chart (FPC)}

The FPC is similar to the OPC regarding the operations and inspections. However, it involved a more detailed description of the chart involving transportation, storage, and delays. All operations are displayed in symbol forms containing the necessary information concerning flow analysis and distance of material transportation. According to the FPC in Figure 2, the locations for the storage and operations the production of jelly mushroom could be divided into three rooms: raw material room, packaging room, and heating and mixing room that include the filling area, depicted by the continuous production process shown in Figure 3. The drinking water, sugar, colouring agent, and the package would be prepared after the operator had cleaned the raw material room. The mixture will then be transferred to the heating and mixing room. Once the final product was sealed in a container, it would be transferred back to the raw material room and forward to the packaging room.

\subsection{Zoning and barriers}

From the process analysis with OPC and FPC, the layout of the new production process was carried out based on the original building area. The area was divided into three zoning areas according to the risk hygiene level: basic hygiene area comprising of the packaging room, medium hygiene area comprising of the raw material room, and high hygiene area comprising of the heating and mixing rooms. The layout of the zoning and barriers are presented in Figure 4. The layout of each room was arranged according to the cleanliness from basic hygiene room to high hygiene room that had an Lline production path to prevent cross-contamination from occurring during the production process.

\subsection{Plant layout}

The cross-contamination of processing and plant 


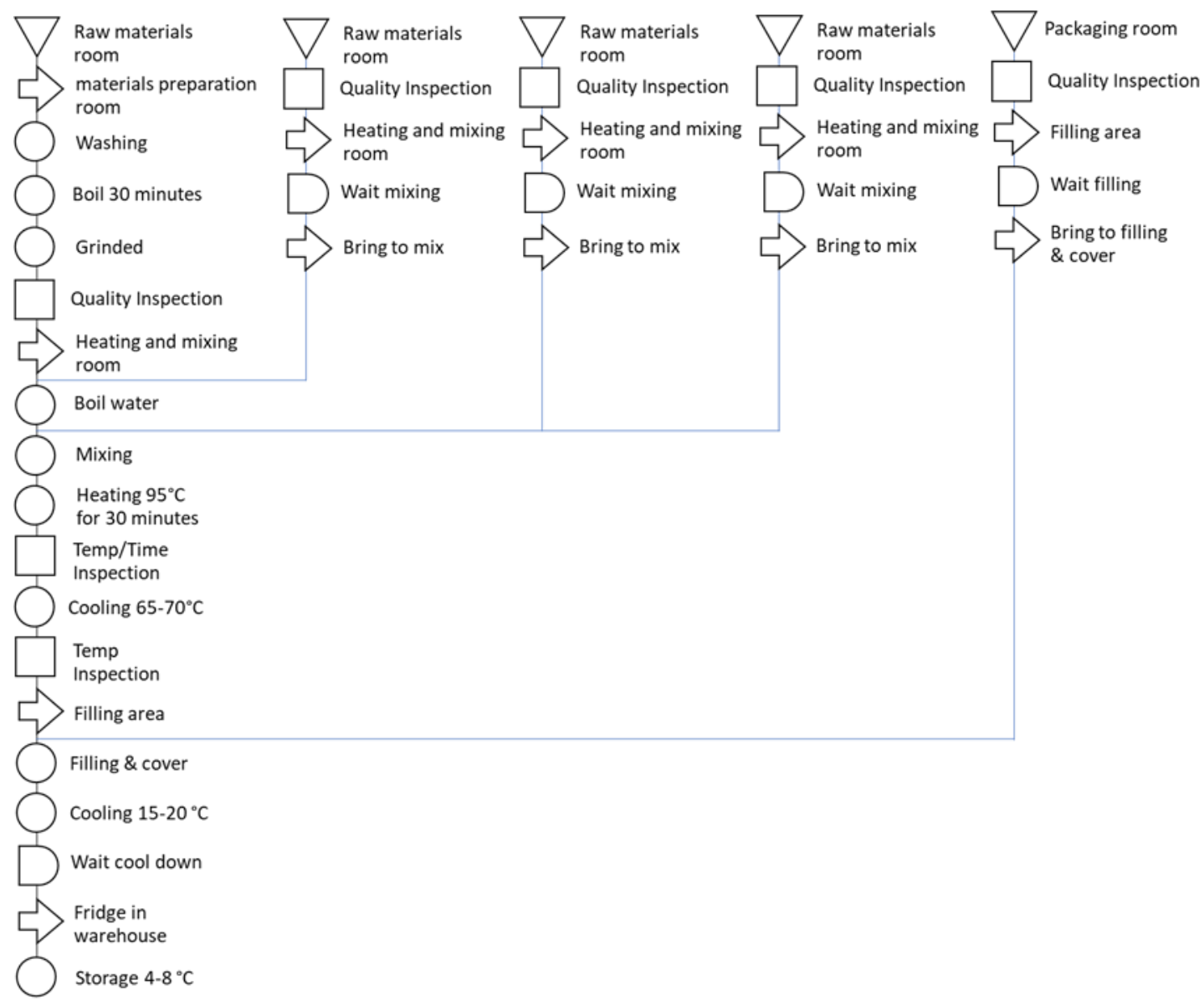

Figure 1. Operation process chart of jelly mushroom production

\begin{tabular}{|c|c|c|c|c|c|}
\hline \multirow[b]{2}{*}{ Sr.No. } & \multirow[b]{2}{*}{ Description } & \multicolumn{4}{|c|}{ Symbol } \\
\hline & & $0 \Rightarrow$ & $D$ & $\square$ & $\nabla$ \\
\hline 1 & To material preparation room & $\Rightarrow$ & $\square$ & $\square$ & $\nabla$ \\
\hline 2 & Washing jelly mushroom & $\Rightarrow$ & $\square$ & $\square$ & $\nabla$ \\
\hline 3 & Boil jelly mushroom for 30 minutes & $\Rightarrow$ & & $\square$ & $\nabla$ \\
\hline 4 & Grind the jelly mushroom & $\Rightarrow$ & & $\square$ & $\nabla$ \\
\hline 5 & Prepare ingredients & $\Rightarrow$ & $\square$ & $\square$ & $\nabla$ \\
\hline 6 & $\begin{array}{l}\text { Quality inspection of materials and } \\
\text { ingredients }\end{array}$ & $\Rightarrow$ & & & $\nabla$ \\
\hline 7 & To heat ing and mixing room & 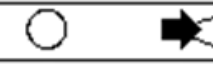 & J & $\square$ & $\nabla$ \\
\hline 8 & Wait mixing & $\Rightarrow$ & & $\square$ & $\nabla$ \\
\hline 9 & Boil water in pot & $\bar{\partial}$ & ) & & 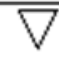 \\
\hline 10 & $\begin{array}{l}\text { Mix ingredients (grinded jelly mushroom, } \\
\text { sugar, color agent) }\end{array}$ & $\Rightarrow$ & & & 7 \\
\hline 11 & heating $95 \stackrel{\circ}{ } \mathrm{C}$ for 30 minutes & $\Rightarrow$ & & $\square$ & $\nabla$ \\
\hline 12 & Inspect temperature and time & $\Rightarrow$ & & & 7 \\
\hline 13 & Cool down at $65-70 \stackrel{\circ}{ }=$ & 디 & D & $\square$ & $\nabla$ \\
\hline 14 & Inspect temperature & $\Rightarrow$ & & - & $\overline{7}$ \\
\hline 15 & To filling area & & & 5 & 7 \\
\hline 16 & Filling and cover & $\Rightarrow$ & D & $\square$ & $\bar{\nabla}$ \\
\hline 17 & Cooling at $15-20 \stackrel{\circ}{C}$ & $\Rightarrow$ & $\square$ & $\square$ & $\nabla$ \\
\hline 18 & Wait cool down & 0 & & $\square$ & \\
\hline 19 & To fridge in warehouse & 0 & & $\square$ & \\
\hline 20 & Storage at $4-8 \stackrel{\circ}{ } \mathrm{C}$ & $\bigcirc$ & $D$ & $\square$ & \\
\hline
\end{tabular}

Figure 3. Flow process of jelly mushroom production 


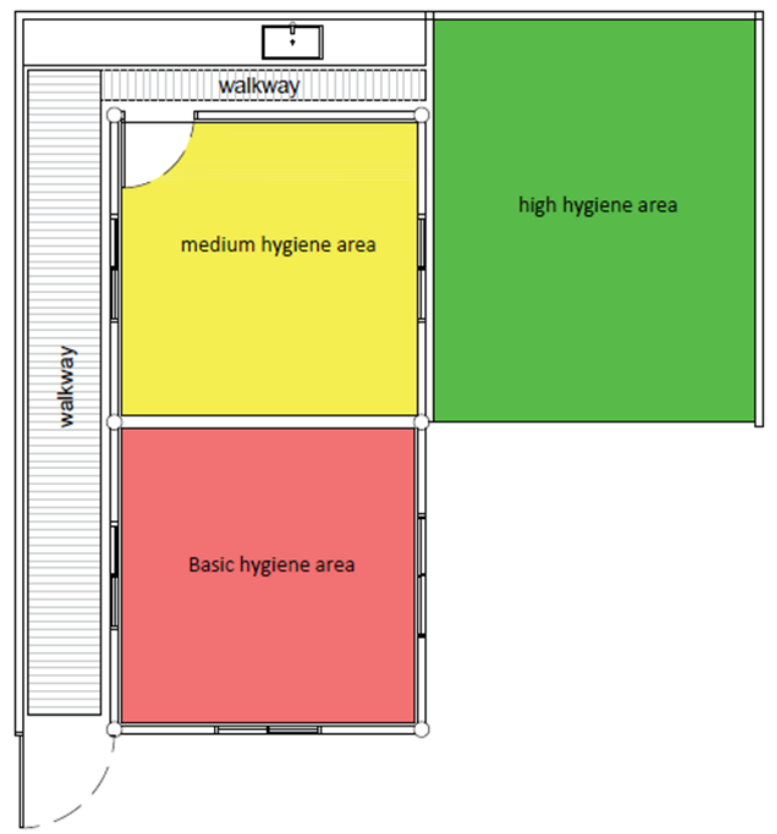

Figure 4. The zoning and barriers of jelly mushroom plant layout

layout such as people's movement in the plant, equipment positions, and materials flow is avoidable when the area of the plant was divided according to risk hygiene level. The designed plant layout is presented in Figure 5. Two washbasins were positioned at the factory entrance and in front of the high hygiene room for cleaning hands, whereas the food washing area was separated from the hand-washing facility. All ingredients were kept in the raw material room. The ingredients were prepared and delivered from the raw material room to the mixing and heating room that had different hygienic level via the window and placed on the table in the mixing and heating room. In the mixing and heating room, the products were heated and cooled at the mixing and heating machine. The jelly mushroom juice was filled into bottles and sealed before cooling them immediately. The final product was brought to pass through a window to the raw material room and then delivered to the packaging room to be kept in the refrigerator. The raw material and package receipt used the exit door of the packaging room as well as transporting products from the packaging room. Usually, the raw material, packaging receipt, and transporting products would be done at different times.

\subsection{Microbiological quality}

The microbiological quality of jelly mushroom drink showed that the cross-contamination assessment that occurred in the production processes development could be reduced in the production process. The microbial test presented in Table 2 shows that the amount of total plate count and yeast and mold of the product after process development decreased from $1.9 \times 10^{7}$ to $<1 \mathrm{CFU} / \mathrm{mL}$ and 29 to $8.3 \mathrm{CFU} / \mathrm{mL}$. respectively. Salmonella spp. and $S$. aureus counts were below the detection level.

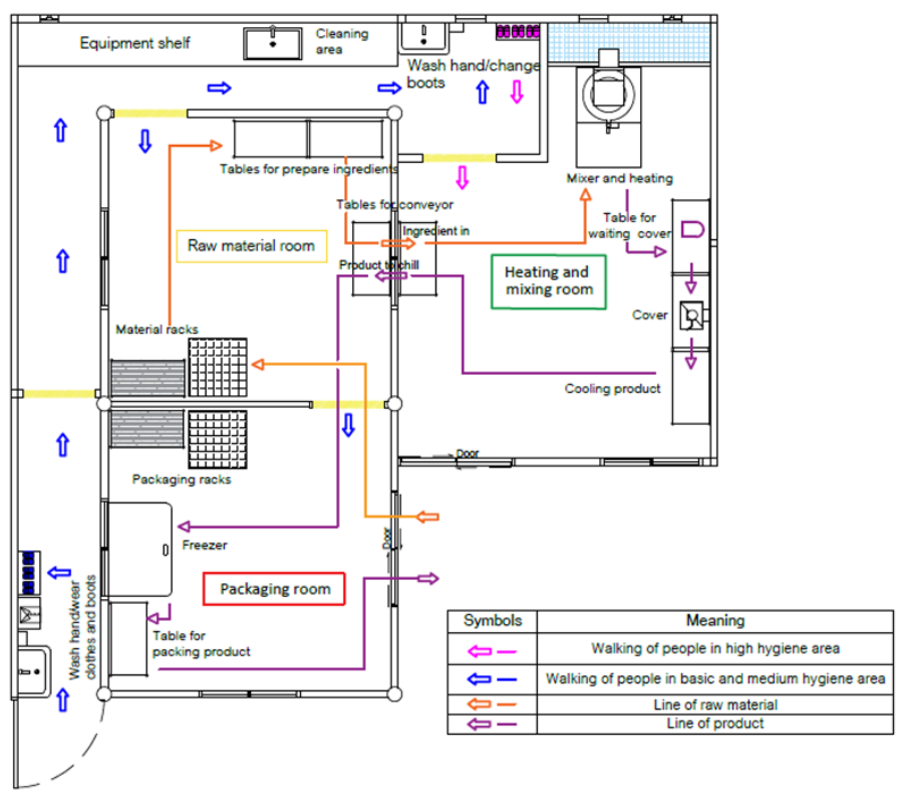

Figure 5. The Plant layout of process and walking of people

Meanwhile, $C$. perfringens, $B$. cereus, and $L$. monocytogenes were not detected in the samples. The results of the microbial test complied with the beverage product standards of The Food and Drug Administration Thailand.

Table 2. The results of measuring the amount of microbiological in the jelly mushroom drink process developed

\begin{tabular}{lcc}
\hline & \multicolumn{2}{c}{$\begin{array}{c}\text { The amount of } \\
\text { microbiological }\end{array}$} \\
\cline { 2 - 3 } The microbiological analysis & $\begin{array}{c}\text { Before } \\
\text { development }\end{array}$ & $\begin{array}{c}\text { After } \\
\text { development }\end{array}$ \\
\hline 1. Salmonella spp. (in $25 \mathrm{~mL})$ & $<1$ & $<1$ \\
2. S. aureus $($ in $0.1 \mathrm{~mL})$ & $<1$ & $<1$ \\
3. B. cereus $(\mathrm{CFU} / \mathrm{mL})$ & Not detected & Not detected \\
$\begin{array}{l}\text { 4. } \text { C. } \text { perfringens }(\mathrm{CFU} / \mathrm{mL}) \\
\text { 5. } \text { L. } \text { monocytogenes }\end{array}$ & Not detected & Not detected \\
(in $25 \mathrm{~mL})$ & Not detected & Not detected \\
$\begin{array}{l}\text { 6. Total plate count } \\
\text { (CFU/mL) }\end{array}$ & $1.9 \times 10^{7}$ & $<1$ \\
7. Yeast and molds & 29 & 8.3 \\
(CFU/mL) & & \\
\hline
\end{tabular}

\section{Conclusion}

The results of this study provided production processes following the requirements of the primary GMP and process analysis comprising of the OPC and FPC of line production of jelly mushroom drink process. The zoning of the factory according to the hygiene risk level and the design of the plant layout could prevent cross-contamination in the production process. The improvement of the plant layout and flow processing carried out in three steps could reduce crosscontamination, as exhibited by the results of the total plate count of yeast and mold that was reduced from $1.9 \times 10^{7}$ to $<1 \mathrm{CFU} / \mathrm{mL}$ and 29 to $8.3 \mathrm{CFU} / \mathrm{mL}$ 
respectively. Salmonella spp. and $S$. aureus counts were below the detection level, while $C$. perfringens, $B$. cereus, and L. monocytogenes were not detected in the samples. The shelf life of products was increased from 5 days to 12 weeks at the frigerated temperatures of $4-8^{\circ}$ C.

\section{Conflict of Interest}

The authors declare no conflict of interest.

\section{Acknowledgments}

This research was supported by Naresuan University with a project grant number R2561A027. We thank our research location were Ban-Tha-Chang mushroom cultivation community enterprise located in Phrom Phiram District, Phitsanulok, Thailand and Pibulsongkram Rajabhat University.

\section{References}

Apple, M.J. (1977). Plant Layout and Material Handling. $3^{\text {rd }}$ ed. New York: John Wiley and Sons.

Cocker, R. (2003). The regulation of hygiene in food processing: an introduction. In Lelieveld, H.L.M., Mostert, M.A., Holah, J. and White, B. (Eds.) Hygiene in Food Processing. Principles and Practice. $1^{\text {st }}$ ed. USA: Woodhead Publishing Limited.

Devi, P., Muhamad I., Ika A.P., Muhammad R.D. and Rifki K.F.A. (2015). The Development of Plant Layout Design Framework. American Scientific Publishers, 23(5), 4281-4286(6). https:// doi.org/10.1166/asl.2017.8254

Singhtaun, C. (2008). Process Analysis. Retrieved on June 19, 2019 from FSIS Website: http:// pirun.ku.ac.th/ fengesr/courses/2008_01/206341/ ch8.pdf

Wierenga, G. and Holah, J.T. (2003). Hygienic Plant Design. In Lelieveld, H.L.M., Mostert, M.A., Holah, J. and White, B. (Eds.). In Hygiene in Food Processing. 1st ed. USA: Woodhead Publishing Limited. 